\title{
Alternative Dispute Resolution in SMEs in the Construction Industry in Masvingo Urban, Zimbabwe
}

Tafara Herbert Tavengahama*, Nhamo Mashavira ${ }^{\dagger}$, Takupiwa Nyanga ${ }^{\ddagger}$ and Chakanaka Ernest Muchadenyika§

\begin{abstract}
Dispute handling may present particular problems for SMEs. The research explored the Alternative Dispute Resolution (ADR) methods used in SMEs and their implications on the performance of SMEs in the construction industry in Zimbabwe. The study revealed that collective bargaining and negotiation are the main ADR methods used in the SMEs while conciliation and arbitration are utilized externally at NEC and the ministry of labour. It was also noted that most SMEs do not have established ADR structures and collective bargaining and negotiation had an impact on employee performance.
\end{abstract}

Keywords: Alternative Dispute Resolution, Collective Bargaining, Conciliation and Adjudication

\section{Introduction}

Mahembe (2011) postulates that policy makers, governments, and even the World Bank are generally in agreement that small

*Julius Nyerere School of Social Sciences, Great Zimbabwe University (GZU), Zimbabwe; tafermpra@gmail.com

† (GZU), Zimbabwe; mashaviranhamo@gmail.com

‡(GZU), Zimbabwe; takupiwa@gmail.com

§(GZU), Zimbabwe; cmuhadenyika@gzu.ac.zw 
businesses are the growth engine in any economy. SMEs, therefore have an incontestable pivotal role in a nation's development. SMEs play an important role in developing countries in creating employment, breeding entrepreneurs, making new products and services available to consumers (Makate, 2014). In Zimbabwe, attention to SME assistance has been in the form of policy changes which have been made to level the playing field mainly among the large scale sectors, so that the policy environment is not biased towards larger firms (Makate, 2014). SMEs are often cited in academic literature as the key to vibrant economies and their perceived contribution to employment generation has made them a focus for policy makers (Beaver \& Prince, (2004) cited in Poku (2012)).

Dinesh Bakshi (2012) broadly defines small businesses as those firms which are independently owned and operated, with a small number of employees and relatively low volume of sales. In the United States, for example, small firms are those with less than 100 employees whereas in Europe the number is limited to 50 employees only and in Australia, small businesses are those with between 1-19 employees. Apart from this commonly used definition of small firms based on employee numbers, other criteria may also be used such as the amount of capital employed, annual sales turnover, value of assets and profits. This would, in turn, mean that definitions will ultimately vary from place to place.

Finnmore (2010) defines Alternative Dispute Resolution (henceforth ADR) as a method of settling labour disputes through semi-formal means, for example, collective bargaining, negotiation, conciliation, mediation and arbitration contrary to resolving disputes through conventional ways of going through the formal court processes.

ADR methods available for SMEs are collective bargaining, negotiation, conciliation, mediation, and arbitration. However, in SMEs, collective bargaining and negotiation are the main ADR methods directly impacting employee performance. Collective bargaining and negotiation are important aspects of employee participation and involvement, therefore enhance employee performance (Nyanga \& Tapfumanei, 2019). Harris et al (2008) argues that dispute resolution is a universal system put in place to 
serve as a precursor for the promotion of harmonious industrial relationships at SME workplaces and is informed by the understanding that industrial peace is the panacea for employee performance and business success in SMEs.

SMEs have traditionally adopted a less formal approach to dispute resolution (Edwards et al., 2008) reflecting the personal nature of working relationships, and yet they remain over-represented among the organization that has disputes dealt with by third parties for example, conciliators (Podro \& Suff, 2013). Early informal dispute resolution, especially in the United Kingdom may arguably, represent an improved situation for SMEs, freeing them from a legal requirement to adopt a level of formality at odds with their practices and culture. However, a significant number of SMEs continue to view formality as a prerequisite to defending their actions in the case of litigation (Harris et al., 2008), or prefer standardized procedures and guidelines when faced with workplace issues where they lack knowledge and experience (Saundry et al., 2011).

The challenge of managing conflict at work is one familiar to workplaces of all sizes especially SMEs (Latreille et al., 2012). However, it is likely that the burden is felt acutely in smaller workplaces/SMEs without the formal Human Resources backup enjoyed by their well-established workplace counterparts. Marachel (2005) states that the question then facing Industrial relations regulators is how best to support SMEs in their efforts to manage and resolve conflict. The desire in SMEs for early and informal resolution of disputes at work is strong but is not always matched with the know-how for adopting such an approach. According to Saundry et al (2011), SMEs' interest in using alternative approaches to legal redress is not matched by experience or exposure to strategies beyond the most formal routes. ADR by its nature suits SMEs in that ADR encourages informal approaches to labour disputes as opposed to the conventional approaches for example adjudication where formality is not compromised when resolving disputes.

Before Zimbabwe's independence, black workers including those in the SMEs did not enjoy formal dispute resolution processes due to the fact that they were viewed and treated as second class 
citizens by the Government of the white minority. According to Gwisai (2006) blacks had no recourse if they felt that an infringement was inflicted on them by their employers. Underpayments, unfair dismissals, summary dismissals and other deplorable working conditions were the order of the day perpetrated against the black workers. Under those circumstances, there was no shoulder to lean on for the poor black worker, the situation was further acute in the SME sector due to its lack of capacity to administer alternative dispute resolution processes. According to NEC (2011), about ninety-five percent (95\%) of SMEs in the sector have difficulties in applying and using the current dispute resolution mechanism, especially at the shop floor level. The majority of these SMEs do not have operational works councils, they do not have disciplinary committees or authorities also grievance handling mechanisms are dysfunctional. This then means that in almost all cases the Designated Agent (DA) ends up taking the role of the works council, disciplinary authority and grievance handling authority.

Further, information available at National Employment Council offices show that about one in every twenty SME organizations has active workers committees and trade union members, also about one percent of these small to medium organisations have established works councils. However, these Works Councils rarely meet to transact any business due to the nature of their operations, and they normally do not have a fixed place to operate from which they can call an office, as their 'offices' are the construction sites where ordinarily it would be rather difficult to conduct such meetings. Kersley et al. (2006, p. 215) states that in the United Kingdom, workplaces with ten or more employees have eightyeight percent $(88 \%)$ of the SMEs using formal procedures for handling employee grievances while ninety-one percent (91\%) have formal procedures for disciplinary matters. A similar situation in Zimbabwe is prevalent in big or established construction companies, where an average of ninety percent $(90 \%)$ have active works councils. Disciplinary committees are also actively involved in handling disciplinary issues and they have established grievance handling procedures and in some cases, these grievance handling tribunals have equal representation of workers committees and management. In big organizations trade unions as well as worker's 
committees are also actively involved in representing the interest of workers both at the shop floor and before other dispute resolution establishments, for example before the Designated Agent, Labour officers and arbitrators.

The variance in the application of Alternative Dispute Resolution methods between established companies on one hand and Small to Medium Enterprises on the other end necessitated the current study which sought to investigate the effect of ADR on employee performance. It goes without saying that ADR has an impact on employee performance as employees tend to perform better where they feel they are involved in decision making through collective bargaining and negotiation as opposed to where management uses its prerogative to dictate how things should be done. SMEs that embrace collectivism as a form of ADR are bound to reap better than those that avoid collective bargaining.

\section{Objectives}

The study sought to:

- Identify and assess the ADR methods used in SMEs in the construction industry

- Assess the utility of the Alternative Dispute Resolution system in resolving labour disputes in SMEs

- Assess the implications of the ADR process on employee performance in the SME sector

- Analyse how ADR affects employee productivity in SMEs in the construction industry

- Suggest recommendations on how the Alternative Dispute Resolution system can be used to increase employee performance in the SME sector

\section{Research Methodology}

This research is informed by phenomenological research design. The phenomenological design was opted for because of its basic assumption that life experiences are subjective and unique to an individual. This means that there are several ways of interpreting 
the same experience (Howitt \& Cramer, 2011). The design was suitable for the current study as it promotes and gives participants such as labour officers, Designated Agent, workers' representatives, owner managers and general workers to freely give their views without being influenced by the thoughts of the researcher and other external forces. The critical positioning and perceived and expected regularity in the utilisation of the dispute resolution process also motivated the researchers to choose the phenomenological design.

The population comprised approximately 2000 workers in SMEs in the construction industry. A sample of sixty-one participants was purposively selected to participate in this study. The sample comprised labour officers, NEC designated agents, workers' representatives, legal practitioners and employers. This sampling method enabled the researchers to get rich information from targeted and well-informed participants. Structured interviews were used to gather data from the participants. In order to obtain standardised information, the researchers conducted interviews using a standardized interview guide. Borg and Gall (2006) concurred that the major reason for using standardized interview guide is to prevent the possibility of obtaining sub-standard information by giving subjects different questions.

Thematic analysis was used to draw themes and patterns of meaning from the interview scripts. The researchers familiarized themselves with every detail of data collected in the analysis where the interviewer had to sort the data collected so as to be familiar with every detail which will help in the creation of themes and taking note of the patterns. After that the researchers developed a detailed analysis of each theme, making sure that the themes have informative names that explain the research findings in detail. The researchers then joined together the analytic narratives, data extracts and contextualized the analysis in relation to the existing literature leading to the final presentation of the results.

\section{Results and Discussions}

Collective bargaining and negotiation are the main Alternative Dispute Resolution methods directly impacting on employee 
performance. Thus collective bargaining and negotiation are important aspects of employee participation and involvement. Harris et al. (2008) argue that dispute resolution is a universal system put in place to serve as a precursor for the promotion of harmonious industrial relationships at SMEs workplaces and is informed by the understanding that industrial peace is the panacea for employee performance and business success in SMEs.

\subsection{Utility of Alternative Dispute Resolution system in resolving labour disputes in SMEs.}

Results from all the groups of participants including employees, trade unions, legal practitioners, NEC and Labour officers as well as almost half of the owner/managers put their weight on the view that Alternative Dispute Resolution is closely related to employee performance. Participant 9 from the employees side had this to say the following: "Ini maonere angu ndeekuti kana nyaya dzedu tikadzigarira pasi tichidzigadzirisa pacompany zvinoita kuti tifarire kushanda." (In my view if disputes are resolved at the company level, this will enhance performance). The affirmation is in congruence with findings by Nyanga and Tapfumanei (2019) Wedderburn (2007) that Alternative Dispute Resolution has an effect on employee performance. He asserted that the way disputes are handled at a workplace plays a key role in eliciting employee performance because employees tend to perform better in environments where their concerns and issues are resolved professionally and with due diligence and respect.

The study also revealed that almost all enterprises used in the sample did not have an HR department to help in carrying out the Alternative Dispute Resolution activities. In most SMEs, the managers or the owners were responsible for the handling of disputes of employees though in an informal way. The respondents said that the size of the enterprise and lack of financial resources was an impediment to the establishment of HR departments, participant 3 confirmed that: "It is difficult to establish an $H R$ department in my company because finances do not permit, even though I am aware that it impacts negatively on the performance of my employees". The findings support prior researchers such as Tayeb (2005) as cited in Appiah et al. (2013) and, Aldrich and Van (1991) cited in Cardon and Stevens (2005) who argued that many SMEs do not 
have HR departments to deal with employee related issues such as dispute resolution, recruitment and selection and as such major functions are carried out by owners or managers. This impacts negatively on employee performance as the lack of expertise in handling disputes by qualified personnel leads to employee dissatisfaction and demoralise employees (Finnmore, 2010). ADR is ineffectively practiced in SMEs at workplace level due to the fact that in almost all SMEs there is no HR department as well as structures for ADR, this is confirmed for example by participant 1 who revealed that, "we actually do not have an HR department because we are just a small entity."

\subsection{ADR Methods Used in SMEs in the Construction Industry}

The study revealed that ADR in SMEs becomes effective when matters are referred to the Ministry of Labour and Social Welfare and the National Employment Council (NEC). Participant 2 contented as follows: "Isu kana paita kusanzwisisana nemushandi tinongoona nyaya dzobva neku NEC kana kulabour vashandi vanomhan 'ara." (When disputes arise at our workplaces, they are resolved through the NEC and Ministry of Labour at the instance of the workers). Bhuiyan (2010) confirms that good labour relations at the workplace promote positive employee relations. Furthermore, Fox (1974) quoted in Tustin and Geldenhuys (2012) in his pluralistic theory of labour relations posits that the preferred methods of conflict resolution in SMEs which impacts employee performance are collective bargaining, arbitration, conciliation and strikes. Strikes though difficult to conduct and manage in the SMEs are also accepted as legitimate.

The results also show that collective bargaining and negotiation are ADR methods that impact the most on employee performance. This resonates well with the findings of Hayward et al. (2005) that employees perform better where they are given a chance to participate and are involved in decisions and issues affecting them. They participate through their chosen representatives for example workers committees and trade unions while they get involved through direct negotiation and quality circles. This according to Fowler (2006) promotes buy-ins from the workers and therefore lead to excellent employee performance. Collective bargaining is a 
key component of employee involvement and participation which in turn promotes employee performance. These findings are consistent with the view of Banks and Saundry (2013) that collective bargaining promotes employee voice, worker participation in the management of decision making and reduce industrial conflict, raise workers' commitment and productivity and ensure rapid grievance procedure and motivate the workers. However, the research found out that some respondents especially SMEs owner/managers were not in agreement that collective bargaining is a key component of employee involvement and participation which in turn promotes employee performance. Most SME owner/managers are proponents of unitarism hence the involvement of workers in decision making is limited. Participant 4 submitted as follows: "I think our employees appreciate what we give and negotiate with them individually as opposed for them to come as a group because they have different expertise and circumstances that require to be dealt with one-on-one." Khattak, Igbal and Bashir (2012) confirm this view when they held that most SMEs hail from mutual agreement as a result of the commonality of interest perceived between the two main participants, the employer and the employee. Due to the adoption of the unitary approach to the conduct of the labour relationship in the SMEs sector the collective bargaining cannot be linked to employee involvement and has no effect on employee participation.

\subsection{Effect of ADR on Employee Productivity}

The findings also revealed that productivity increases due to the effectiveness of Alternative Dispute Resolution. Employees, trade union representatives, labour officers, NEC officers and some owner/managers who participated in the research affirmed that effective ADR has a positive effect on productivity. According to the assertion of participant 7, it was highlighted thus, "Dai taiwana mukana wekugadzirisa nyaya dzedu nemushandirwi pabasa pedu, ndinoona sekuti basa raifamba chaizvo kudarika zvirikuitika izvi." (If a platform to resolve disputes at company level was promoted, I believe productivity would increase). These findings are corroborated by the views of Sha (2010), wherein it was found out that productivity gains are closely connected to industrial relations and that there is a connection between a positive and friendly 
relationship between management and labour which results in increase in production, whereas hostile relations are connected to the decrease in production. However, the majority of the owners/managers and legal practitioners felt that the two concepts possess no positive connection because they felt that there are other factors like technology, availability of resources for example working capital, reward management practices etc, that impact productivity and not necessarily on the effectiveness of ADR. This line of thinking is supported by Nyamwanza (2014), who found out that more often than not, some SMEs employers argue that increased productivity is the result of technological change and because of sophisticated equipment not necessarily due to increased effectiveness of working of employees and the environment they work in. Participant 4 from the employers' side argued that, "I don't think Alternative Dispute resolution affects productivity, in my view there are a number of factors that affect productivity especially technology, working capital etc." However, the conclusion that can be drawn is that ADR effectiveness is one of the factors that impacts productivity. Owners/managers did not dispute this fact but they felt it is not the only factor.

\subsection{Implications of the ADR Process on Employee Performance in the SME Sector}

The study shows that worker representatives in SMEs are not involved in ADR and therefore destroys the confidence of the whole system, thereby impacting negatively on employee performance. It was revealed that almost all SMEs do not have functional and established workers committees, therefore this means that workers are unable to air their views and concerns collectively and this demoralises and demotivates them and eventually affects their performance. Participant 8 from the employee side said that, "Isu hatimbopihwi mukana wekuti tigare pasi nevashandirwi kugadzirisa nyaya dzinenge dzaitika pabasa, izvozvi kwatiri hazvitifadzi naizvozvo zvinokanganisa mashandire edu." (We are not given an opportunity to sit and resolve our disputes with our employer and this is not amusing and therefore affects our performance at work.) This validates Mulvey's (2010) assertion that workers who have a greater choice concerning how to do their own work have high job satisfaction and consequently high job 
performance. It is further corroborated by Khattak, Igbal and Bashir (2012) who indicated that employee involvement and participation at work has a significant positive effect on job satisfaction, leading to improved organizational performance. Results from the majority of the participants showed that works council platforms in SMEs are an effective way of dispute resolution and promotes employee commitment and performance. Employees in the SMEs get committed, engaged and motivated if they perceive the effectiveness of ADR at their workplaces. Williams (2011) supports this view when he posits that people are more likely to be motivated if they work in an environment in which they are valued for what they are and what they do. This means paying attention to the basic need for recognition, involving workers in decisions that affect their wellbeing through the utilization of works council forums in resolving SMEs workplace disputes. The Blessing White (2006) study further concurs that almost two third (60\%) of the surveyed employees in the SMEs sector in the United Kingdom agree that a strong manager-employee relationship is a crucial ingredient in the employee engagement and retention formula. This is also consistent with the view of Macey and Schneider (2008) that Commitment can be increased and harnessed "to obtain support for organizational ends and interests" through such ploys as participation in decisions about actions.

The findings of Rowena and Susan (2007) confirm that employee participation has a positive effect on employee performance and job satisfaction. Though there is an agreement to this assertion however the research revealed on the other hand that SMEs do not have established and functional works councils and this is detrimental to employee commitment and performance since works councils platforms are the linchpin of employee participation. The same is supported by Banks and Saundry (2013) who concluded that, to increase workers' commitment and humanize the workplace with the intention of improving the firms' performance and good citizenship behavior, managers need to permit a high degree of employee involvement in decision making. It is elaborately clear from the study that ADR impacts both positively and negatively on employee performance. Positively if employees perceive that their grievances and concerns are considered and valued by the employer through employee 
participation and involvement and the reverse is true. This is supported by the views of Budd (2010) commenting on the practice of the pluralistic theory as propounded by Fox (1974) that there is industrial democracy at workplaces, as employees in the SMEs are given a voice on decisions that affect them. The SME employer may use staff meetings, quality circles, and works councils to harness conflicting interests of employees to ensure superior employee and organizational performance.

\section{Conclusions and Recommendations}

The study concluded that collective bargaining and negotiation are the prevalent ADR methods in practice at most SME workplaces while conciliation and arbitration are embraced at the Ministry of Labour and NEC. All ADR strategies promote employee performance and lead to productivity and industrial harmony. It was also concluded that employees resort to adversarial dispute resolution methods such as collective job action as well as adjudication if a conducive environment permitting other nonadversarial methods is not cultivated at the workplace. Therefore, SMEs need to cultivate a conducive environment that includes structures for engagement of employees, management commitment to workforce policies and procedures and appropriate organizational culture especially low power distance culture. Such an environment will allow successful consultation and negotiation between management and labour thus ensuring a qualitative organisational performance. Adversarial methods to resolve labour disputes should be discouraged and avoided at all costs as they do not work in the best interest of the parties. It is therefore strongly recommended that owners/managers in the SMEs be trained in ADR as an alternative to the establishment of HR departments in SMEs. Furthermore, it is also desirable that a law is promulgated to allow HR consultancy to be involved and participate at the shop floor level to enhance ADR. This allows SMEs who may not have the capacity to engage HR managers to superintend ADR to engage HR consultancy who would help them on an Adhoc basis. It is further recommended that regulations be made through the Ministry of Labour to empower NEC Designated Agents and Labour officers to be allowed to conduct dispute resolution at shop 
floor level due to the fact that by virtue of SMEs sizes it is difficult for them to conduct dispute resolution or to establish HR departments.

\subsection{Limitation of the Study}

The researchers experienced difficulties in obtaining accurate information from SMEs employers by virtue of them being informal employers, the employers do not keep formal records and are not conversant with formal approaches in doing business. It was also difficult locating them since most of them do not have designated offices to operate from. However, the researchers employed a strategy of visiting them at their construction sites as well as completing the questionnaires together with them in a bid to explain and clarify any ambiguity from the questionnaires.

\section{References}

Appiah, F. A., Poku, B., \& Bomfo, A. (2013). An investigation into the recruitment and selection practices of small to medium enterprises: evidence from Ghana. Global Advanced Research. Journal of Management and Business Studies, 2(3).

Banks, L., \& Saundry, R. (2013). Mediation-A panacea for the Ills of workplace dispute resolution? A comprehensive review of the literature examining small and medium firms workplace mediation. Institute for Research into Organisations, Work and Employment: Lancashire Business School, 1(2).

Budd, J. W. (2010). Labor relations-striking a balance (3 ${ }^{\text {rd }}$ ed.). New York: Mcgraw-Hill Int'l.

Bhuiyan, M. H. (2010). Employee participation in decision making in RMG Sector of Bangladesh: correlation with motivation and performance. Journal of Business and Technology (Dhaka) 5(2), 122-132.

Blessing, W. (2008). The employee engagement equation in India. retrieved from www.blessingwhite.com (November 15, 2008).

Borg \& Gall. (2009). Educational research: An introduction. London: Longman.

Budd, J. W. (2010). Labor relations-striking a balance (3 ${ }^{\text {rd }}$ ed.). New York: Mcgraw-Hill Int'l.

Cardon, M. S., \& Stevens, C. E. (2005). Managing Human resources in small organizations. What do we know? Human Resource Management Review, 14(295-323). 
Dineshbakshi. (2012). Small businesses and their importance. Retrieved from http://www.dineshbakshi.com/igcse-business-studies/ business-activity/revision-notes/1258-small-businesses-and-theirimportance [accessed: 05 April 2019].

Edwards, P., Ram, M., \& Black, J. (2006). The impact of employment legislation on small firms: A case study analysis. DTI Employment Relations Research Series, 20.

Finnemore, M. (2013). Introduction to labour relations in South Africa $11^{\text {th }}$ Ed. Durban. LexisNexis.

Fowler, A. (2006). Effective negotiation in the SME sector. Institute of Personnel Management, London.

Harris, L., Tuckman, A., Snook, J., Taillby, S., Hutchinson, S., \& Winters, J. (2008). Small firms and workplace dispute resolution. London: ACAS.

Hayward, B., Peters, M., Rousseau, N., \& Seeds, K. (2005). Findings from the survey of SME employment tribunal applications 2005. Employment Relations Research Series, 33. London, DTI.

Howitt, D., \& Cramer, D. (2011). Introduction to research methods in psychology ( $3^{\text {rd }}$ ed.). Harlow: Prentice Hall.

Gwisai, M. (2006). Labour and employment law in Zimbabwe. Zimbabwe Labour Centre. Harare.

Khattak, M. A., Igbal, N., \& Bashir, F. (2012). SMEs Employee involvement and participation at work: A case study of OTCL after privatization. International Journal of Academic Research in Business and Social Sciences. 2(6), 469-476

Kersley, B., Carmen, A., Forth, J., Bryson, A., Bewley, A., Dix, G., \& Oxenbridge, S. (2006). Inside the workplace-findings from the 2006 SMEs workplace employment relations survey. London: Routledge.

Latreille, P. L., Buscha, F., \& Conte, A. (2012). Are you experienced? SME use of and attitudes towards workplace mediation. International Journal of Human Resource Management, 23(3), 590-606.

Macey, W. H., \& Schneider, B. (2008). The Meaning of employee engagement. The SMEs perspective. Industrial and Organizational Psychology Journal, 1(2008), 3-30.

Makate, C. (2014). Determinants of small and medium enterprises performance in the Zimbabwean informal Metal fabrication industry evidence from firm level data. Research Journal of Economics, 10, 23478253.

Mahembe, E. (2011). Literature review on small and medium enterprises' access to credit and support in South Africa. Retrieved from http:/ / www.ncr.org.za/pdfs/Literature \%20Review \%20on $\% 20$ SME $\%$ 20Access $\% 20$ to $\%$ 20Credit \%20in\% 20 South \% 20Africa_ Final \% 20Report_NCR_Dec\%202011.pdf [accessed: 05 April 2019]. 
Marachel, P. (2005). Building a Better future in smes through mediation, insights from a survey of FMCS mediators. Journal of Collective Negotiations, 11, 41-68.

Mulvey, C. (2010). Alternatives to arbitration in small organisations: overview of debate. Sydney: Unwin.

NECCI. (2007). Utilisation of adr system in the construction sector. Harare: Solidarity Centre.

Nyamwanza, T. (2014). A Review of the Human Resource Approaches on Strategy Implementation among SMEs in Zimbabwe. Journal of Business \&amp; Management 3, (2) (2014), 01-16

Nyanga, T., \& Tapfumanei, C. S. (2019). Collective bargaining: a catalyst for dispute resolution between employers and employees in the retail industry in urban Mutare. Ushus Journal of Business Management, 18(1), 1-14.

Podro, S., \& Suff, R. (2013). Mediation: An Approach to Resolving SMEs Workplace Issues. London: ACAS, CIPD.

Poku, O. A. (2012). An Investigation into the Recruitment and Selection Practices of SMEs in the Kumasi Metropolis. Global Advanced Research Journal of Management and Business Studies 2(3), 175-188.

Rowena, B., \& Susan, M. (2007). Human resource management in growing small firms. Journal of Small Business and Enterprise Development, 14, 307-320

Saundry, R., Antcliff, V., \& Jones, C. (2011). Discipline, representation and dispute resolution: exploring the role of trade unions and employee companions in workplace discipline in SMEs. Industrial Relations Journal, 42(2), 195-211.

Sha, S. (2010). An investigation into the problems facing small to medium sized enterprises in achieving growth in the Eastern Cape: enhancing the strategy for developing small growth potential firms in the eastern Cape. Unpublished BComm. Master's Thesis. Grahamstown: Rhodes University. Retrieved from http://eprints.ru.ac.za/288/1/Sha-TR06146.pdf [accessed: 05 August 2016].

Tustin, C., \& Geldenhuys, D. (2012). Labour Relations - the psychology of conflict and negotiation in small to medium firms ( $2^{\text {nd }}$ ed.). Cape Town: Oxford University Press.

Wedderburn, L. (2007). Labour law 2008: 40 Years on. Industrial Law Journal, 36(4), 3974245.

Williams, M. (2011). Workplace conflict management: awareness and use of acas code of practice and workplace meditation for small firms - a poll of business. London: ACAS. 